\title{
Онлайн-обучение восточным языкам: возможности и вызовы (по результатам внедрения программ электронного обучения китайскому языку)
}

\author{
Н.Н. Власова, Е.Н. Колпачкова, Н.А. Сомкина \\ Санкт-Петербургский государственный университет \\ n.vlasova@spbu.ru, e.kolpachkova@spbu.ru, n.somkina@spbu.ru
}

\section{Аннотация}

Создание программ электронного обучения восточным языкам имеет целый ряд дополнительных проблем, возникающих вследствие специфических особенностей этих языковых систем, однако сдвиги в традиционной модели образования уже выявили большой спрос на онлайн-курсы китайского, японского и других экзотических языков. Имея преимущество в виде богатого практического опыта при полном отсутствии подобных проектов в российском образовании, создатели курсов восточных языков идут по пути расширения, углубления и совершенствования программ электронного обучения с учетом глобальной тенденции к цифровизации образовательных услуг с опорой прежде всего на многолетний практический опыт педагогов-создателей курса.

Ключевые слова: онлайн-обучение, дистанционное обучение, электронная образовательная среда, цифровизация образования, дополнительное обучение, китайский язык

Библиографическая ссылка: Власова Н.Н., Колпачкова Е.Н., Сомкина Н.А. Онлайнобучение восточным языкам: возможности и вызовы (по результатам внедрения программ электронного обучения китайскому языку) // Информационное общество: образование, наука, культура и технологии будущего. Выпуск 3 (Труды XXII Международной объединенной научной конференции «Интернет и современное общество», IMS-2019, Санкт-Петербург, 19 - 22 июня 2019 г. Сборник научных трудов). - СПб: Университет ИТМО, 2019. С. 90 - 100. DOI: 10.17586/2587-8557-2019-3-90-100

\section{1. Онлайн-обучение в России}

Традиционная образовательная модель, когда человек получает одно высшее образование в юности, затем просто совершенствует свой опыт, оставаясь в рамках той же профессии, в XXI веке сменилась концепцией «обучения длиною в жизнь» («lifelong learning»), что созвучно древней китайской мудрости 活到老，学到老，学到八十仍嫌少 huó dào lăo, xué dào lăo, xué dào bāshí réng xián shăo «Живи до старости, учись до старости, до 80 лет учиться и то не поздно».

Современный человек в течение жизни постоянно меняет место жительства, пробует свои силы в различных сферах деятельности, порой осваивая совершенно новые профессии, или же приобретая полезные навыки и вписывая новую строку в резюме. Только так он будет конкурентоспособен на чутко реагирующем на социально-экономическую ситуацию и быстро меняющемся рынке труда, поскольку даже специалисты не берутся прогнозировать, каким этот рынок станет через пять-десять лет. Очевидно одно: те, кто не способен меняться и быстро 
адаптироваться к новым вызовам, окажутся на обочине жизни. Панацеей от такого сценария является постоянное обучение, ставшее сегодня доступным в любой точке мира, где есть связь и интернет.

Считается, что толчком к интенсивному развитию непрерывного обучения стали массовые открытые онлайн-курсы (МООС), которые сработали как пусковой механизм в тот момент, когда созрели новые технологии, когда в 2012 году, спустя два десятилетия, с момента старта первых площадок электронного обучения в 1990-е гг., начали функционировать три крупнейшие площадки Coursera, EdX и Udacity, и наступила настоящая эра мирового массового онлайн-обучения, на сегодняшний день насчитывающая уже не один десяток образовательных платформ.

Сегодня онлайн обучение стало привычным занятием для многих и активно практикуется по всему миру, число доступных интернет-пользователям образовательных программ исчисляется уже десятками тысяч, более 700 университетов по всему миру имеют собственные онлайнкурсы по различным отраслям знаний, что свидетельствует о формировании настоящей «экосистемы онлайн-образования» в глобальном масштабе.

Развитию онлайн-обучения в России способствовал серьезный географический разброс между образовательными центрами и расширение доступа к широкополосному интернету в регионах. Эти факторы способствовали созданию совместными усилиями ряда российских ВУЗов (СПбГУ, МГУ, Политех, НИУ ВШЭ и др.) электронной площадки онлайн-обучения с целью составить конкуренцию крупным зарубежным игрокам на рынке соответствующих услуг. Так, в сентябре 2015 общественности был представлен совместный проект российской высшей школы- национальная платформа «Открытое образование» [1, с.144]. В момент открытия на этой платформе было размещено 46 курсов с 8000 подписчиками, на сегодняшний день это уже почти 3 млн. записей на курсы и более 700 тысяч уникальных пользователей, самих курсов насчитывается уже более 300 [2, с. 174]. Основная аудитория образовательных онлайнплатформ - взрослые, платежеспособные лица, которым нужна обновленная информация по специальности или расширение имеющихся знаний, но нет возможности вернуться традиционным путем в ВУЗ и выделить время на учебу, зачастую речь идет не о хобби, а именно о прикладном использовании полученных на онлайн-курсах профессиональных знаний. Так, среднестатистический слушатель на платформе «Открытое образование» — это девушка 29 лет, а на платформе «Coursera» молодой человек примерно того же возраста. В России большинство слушателей - это жители крупных городов, но, как представляется, подобная ситуация имеет тенденцию постепенно меняться, по мере усиления массового характера онлайн-образования. Аналогичный сдвиг наблюдался у всех крупных игроков в данном сегменте с длительной историей. По статистике платформы «Coursera», большая часть последовательных онлайнучащихся, то есть тех, кто планомерно осваивает курс за курсом, - это люди из отдалённых мест, где фактически нет иных возможностей получить качественное образование.

На фоне огромного выбора различных дисциплин, доступных для всех желающих обучаться дистанционно, в предлагаемом наборе онлайн-курсов существовала серьезная лакуна по восточным и африканским языкам. Причиной этого, очевидно, являлись отсутствие опыта создания подобных программ и объективные трудности методологического характера. Уверенно крепнущий последние десятилетия интерес к изучению китайского языка и культуры в скором времени поставит китайский язык по востребованности на второе место после английского. В крупных мегаполисах, где изучение английского языка стало общепринятой нормой, и владение им, как минимум на уровне В2, по умолчанию предполагается практически для всех соискателей, осознанно желающих добиться успеха в престижных специальностях XXI века, в сфере изучения иностранных языков ставка делается на китайский язык. При приеме на высокооплачиваемую работу знание этого языка является весомым преимуществом при отборе 
претендентов на вакантную должность, однако стремительный ритм жизни, дефицит свободного времени или даже просто дорожная ситуация в городах не оставляют возможности изучать язык традиционным способом, регулярно посещая очные занятия и выполняя задания под непосредственным контролем преподавателя в аудитории. Не менее актуальной является данная проблема для тех регионов, которые в силу географической удаленности от образовательных центров не имеют материально-технической, кадровой или методической базы для изучения китайского языка, необходимого для практической деятельности, например, в приграничных районах. Несмотря на наличие на международных образовательных платформах курсов китайского языка, провайдерами которых являются университеты КНР, для многих россиян обучение затрудняется в силу использования английского как языка преподавания или объяснений. В такой ситуации онлайн-обучение в рамках отечественных образовательных программ является эффективным средством удовлетворения этой потребности, позволяя в условиях серьезного недостатка времени или отсутствия объективной возможности для очных занятий полноценно и с комфортом изучать редкие по представленности в образовательных программах языки и вне зависимости от территориальных барьеров получить доступ к качественному образованию.

На восполнение этой лакуны и были направлены усилия специалистов СанктПетербургского государственного университета, на тот момент продолжавших активно создавать и продвигать массовые открытые онлайн-курсы по различным направлениям подготовки. Методологический задел, составляющий более 100 онлайн-курсов с аудиторией более 800 тыс. человек, ориентированных не только на российских пользователей, но и на иностранную аудиторию, например, курс «Русский язык как иностранный для начинающих», в 2016 году позволили создать первый в нашей стране онлайн-курс по китайскому языку. При этом авторы курса столкнулись с целым рядом дидактических и технических проблем, решение которых, как представляется, во многом определяет дальнейшие перспективы развития языковых программ электронного обучения восточным языкам. Настоящее исследование представляет собой анализ специфики технологической инфраструктуры, необходимой для доставки содержания обучения экзотическому языку в рамках онлайн-курса, в данном сегменте все еще находящегося в стадии становления методологической базы. На первый запуск курса «Китайский язык для начинающих» весной 2017 года записалось около 14000 учащихся, следующий запуск был осуществлен уже на платформе «Coursera» (см. таблица 1). К настоящему времени суммарно обучение на курсе прошли около 30000 человек. Цифры впечатляющие, однако следует учитывать, что до конца обучения доходят в лучшем случае около $10 \%$. К настоящему времени в СПбГУ применительно к китайскому языку созданы два языковых курса (для начинающих и продолжающих, Части 1 и 2 соответственно), а также вводный курс по иероглифике. Все три курса получили высокую оценку слушателей. Весной 2018 года стартовала программа электронного обучения арабскому языку, осенью 2018 - курс японского языка, весной 2019 - курс фарси и часть 2 по арабскому языку.

В целом, как показывает статистика, к онлайн-обучению приходят люди разных возрастных категорий (разброс 9-70 лет) с совершенно разным уровнем знаний, целями и потенциалом. По отзывам слушателей, особо эффективным является совмещение очного обучения на языковых курсах с дистанционным (вне зависимости от географического положения обучающегося, поскольку на русскоязычных программах зачастую учатся экспаты), позволяющее после прохождения курса участвовать в экзамене на уровень знания китайского языка HSK. Это свидетельствует о том, что для слушателей любых онлайн-курсов важно видеть цель, ради которой они проходят обучение.

Нарисовать портрет среднестатистического слушателя онлайн-курса китайского языка пока не представляется возможным, что лишний раз доказывает популярность китайского языка 
среди совершенно различных слоев населения, во многом обусловленную многолетним ростом интереса россиян к Китаю, его многовековой истории, богатой культуре и языку.

Таблица 1. Статистика по запускам курса

\begin{tabular}{|l|c|c|c|}
\hline \multicolumn{1}{|c|}{ Запуск } & Часть 1 & Часть 2 & $\begin{array}{c}\text { Введение в } \\
\text { иероглифику }\end{array}$ \\
\hline весна 2017 & 12900 & - & \\
\hline осень 2017 & 6125 & - & \\
\hline весна 2018 & 6770 & 4279 & \\
\hline лето 2018 & 3300 & 1400 & \\
\hline режим свободного доступа & 15450 & 6000 & \\
\hline осень 2018 & - & & 7170 \\
\hline весна 2019 & & & 1705 \\
\hline
\end{tabular}

На платформе «Coursera» часть 1 курса «Китайский для начинающих» собрала общее количество активных слушателей около 8000, среди которых курс получил положительную оценку у 99\% пользователей, общий рейтинг курса составил 4,8.

В целом по результатам трех лет внедрения русскоязычных курсов восточных языков можно сказать, что вокруг онлайн-обучения уже успело сформироваться определенное сообщество: обучающиеся рекомендуют программу другим пользователям, приводят друзей, образуется комьюнити курса, которое помогает усовершенствовать и модернизировать содержание курса вплоть до самостоятельных разработок вспомогательных материалов к занятиям или полезных находок в ходе выполнения домашних заданий, которыми обучающиеся делятся друг с другом и разработчиками на форуме.

\section{2. Почему китайский язык и иероглифика?}

Онлайн-курс позволяет всем желающим получить новые или углубить уже имеющиеся базовые или даже продвинутые знания по китайскому языку и письменности, выбрав для себя подходящий уровень, а также приобщиться к китайской культуре. И языковой курс, и иероглифический построены на базе учебно-методической программы и материалов, которые первокурсники Восточного факультета СПбГУ, изучающие китайский как основной язык, проходят в рамках дисциплины «Фонетика и разговорный язык».

За основу был взят первый том учебника «301 фраза», материал которого был существенно переработан (преимущественно пересмотрены фразы и диалоги, уроки снабжены полностью авторскими объяснениями грамматики и примерами, все упражнения придуманы лично Н.Н. Власовой). Вводный иероглифический курс базируется на авторской методике А.Г.Сторожука и уже много лет успешно применяется в СПбГУ.

Эффективность используемых методик подтверждается ощутимыми результатами учащихся при сдаче экзамена на уровень владения китайским языком HSK. Роль опытного преподавателя крайне важна как в организации онлайн-обучения, так и в ходе его реализации, особенно на начальном этапе изучения восточных языков, многолетний педагогический стаж специалистов по китайскому языку из СПбГУ способствует эффективному прохождению обучения практически в любом формате. 


\section{3. Первые внедренные онлайн-курсы восточных языков}

\section{1. «Китайский язык для начинающих»}

Онлайн-курс «Китайский язык для начинающих» в двух частях имеет в своей структуре теоретический материал, представленный в форме видео-лекций и анимированных сюжетов, грамматические правила и примеры, иллюстрирующие материал данного урока. Каждый урок снабжен домашними заданиями, выполнение которых предполагается от обучающегося для отработки и закрепления пройденного лексического, грамматического и иероглифического материала. Онлайн-курс - живой организм, он растет и совершенствуется прямо на глазах, в материалы курса постоянно вносятся коррективы и дополнения, по мнению авторов и по отзывам слушателей, повышающие эффективность учебного процесса. Контроль осуществляется в форме тестов и финального задания (экзамена), то есть по своей структуре занятия онлайн-курса во многом соответствуют традиционной модели обучения, отличаясь от очных занятий с преподавателем в аудитории лишь форматом.

Курс состоит из 10 уроков, предлагаемых слушателям календарно - раз в неделю, и рассчитан на 11 недель обучения соответственно, по истечении которых обучающийся может пройти тестирование и получить сертификат о прохождении онлайн-курса.

Каждый урок состоит из двух частей, включающих в себя следующие блоки:

Лексика и иероглифика, включая порядок черт в написании иероглифов.

Благодаря оригинальному дизайнерскому решению, кроме обычного списка новых слов, типичного для любого курса иностранного языка, данный курс снабжен еще и запоминающимися «ожившими» иероглифами, анимированная форма которых помогает запомнить, в каком порядке следует писать черты в иероглифе и как красиво и правильно вписать иероглиф в четыре клетки.

В разделе «Прописи» размещены доступные для скачивания материалы, необходимые для тренировки написания иероглифов. Сейчас даже сами носители китайского языка плохо пишут иероглифы, поскольку чаще печатают их на мобильных устройствах или компьютерах, а не пишут рукой. Навык рукописного письма иероглифических знаков необходим всем изучающим китайский язык, он способствует запоминанию новых иероглифов, кроме того, прописывание иероглифов - медитативное занятие, которое успокаивает нервную систему и развивает моторную память человека.

Программа-минимум, которая ставится авторами курса перед слушателями, - узнавать иероглифы в тексте и уметь напечатать их на компьютере, но надо стремиться к программемаксимум - уметь писать рукой на бумаге все изученные иероглифы. Для этого традиционно берется обычная тетрадь в клетку, в которой в квадрат (2х2 клетки) вписываются изучаемые знаки китайской письменности, при этом зачастую включается и моторная, и зрительная память. Если хорошо развита аудиальная память, то можно еще и проговаривать чтение иероглифа вслух, задействуя тем самым сразу несколько модальностей (систем восприятия), доступных человеку.

В последнее время появилось большое количество всевозможных программ и приложений для мобильных устройств, которые тоже помогают в запоминании иероглифов, когда знак выводится на сенсорной панели указательным пальцем как своеобразным продолжением ручки, а значит, запускается моторная память.

Китайский язык относится к тональным языкам, и у слушателей зачастую возникают трудности с запоминанием тонов. Создатели курса рекомендуют тем, у кого хорошо развита зрительная память, использовать следующую методику: в соответствии с собственными цветовыми ассоциациями условно присвоить тонам определенный цвет. Затем закрепить эти 
связи, во-первых, прописывая иероглифы в прописях ручками соответствующих цветов, вовторых, настроить электронные оффлайн-словари, типа «Рleco», так, чтобы иероглифы были указаны разными цветами в зависимости от тона. Тогда иероглиф будет всплывать в памяти в определенном цвете, напоминая о тоне. Для запоминания тона важно также многократно проговаривать слово вслух, активируя все доступные каналы для большей эффективности процесса запоминания.

В рамках первой части курса изучается около трехсот лексических единиц, что примерно соответствует уровню А1. Для удобства запоминания большие блоки лексики разбиты пополам, после каждого блока даны лексические упражнения для закрепления пройденного материала. Полный список слов к курсу в алфавитном порядке прилагается в виде текстового файла с указанием урока, в котором слово встретилось в первый раз. Особо любознательным слушателям в рамках изученной темы, помимо основной, предлагается дополнительная лексика.

Грамматическая часть урока дается с подробными пояснениями и наглядными примерами для каждого случая.

Все возникшие вопросы обучающиеся имеют возможность обсудить в сообществе на форуме курса. Зачастую те, кто взялся учить китайский, жалуются, что «грамматика никак не превращается из хаоса в систему», что обычно свойственно людям только начинающим изучать этот язык, в целом китайский язык очень и очень логичен, но на начальном этапе слушатели часто находятся в плену грамматики родного языка или других менее «экзотических» иностранных языков. Данная форма обучения предполагает выполнение тестовых заданий к каждому уроку с автоматизированной проверкой результатов. Итоговый уровень грамматики после прохождения первой части курса предполагается как A1/A2.

Отдельный блок представляют собой примеры разговорных фраз для заучивания.

Все аудиоматериалы и видео-сюжеты курса озвучены носителями китайского языка (мужской и женский голос). Этот блок предполагает прослушивание соответствующих предложений в исполнении дикторов-носителей и повтор за ними, опять же желательно без наушников, иначе обучающийся себя не слышит. Изучая китайский язык, для обучающихся важно научиться слышать себя, подмечать свои ошибки в произношении и тонах и стремиться исправлять их.

Каждый урок содержит лексические и грамматические упражнения различных типов, которые слушателям необходимо выполнять самостоятельно с целью закрепления пройденного материала, а также текстовые материалы из рубрики «Это интересно», рассказывающие об истории языка, о культуре Поднебесной и привычках китайцев и т.д. Авторы курса постарались снабдить любознательных слушателей, желающих расширить свои знания о Китае, большим списком дополнительной литературы для самостоятельного чтения.

\section{2. «Введение в китайскую иероглифику»}

В СПбГУ как одной из старейших и сильнейших в стране школ востоковедения сложилась уникальная и самобытная методика преподавания китайской письменности, практические результаты которой говорят об ее высокой эффективности. Разработанный А.Г. Сторожуком, Н.А. Сомкиной и Н.Н. Власовой онлайн-курс «Введение в китайскую иероглифику» предлагает всем желающим познакомиться с этапами эволюции китайской письменности, основными принципами написания иероглифов и правилами порядка черт. Изучающие китайский язык слушатели смогут разобраться в особенностях базовых графических элементов китайской письменности - иероглифических ключей, что во многом облегчит освоение иероглифики в дальнейшем. 
Методика обучения графическим навыкам иероглифического письма в рамках данного онлайн-курса следует принципам системности и постепенности и сводится к последовательному знакомству и заучиванию базовых графических элементов (ключей), а затем и иероглифов, постепенно усложняясь и переходя от простых и очевидных вещей к более сложным. Подобная поступательность гарантирует высокую эффективность учебного процесса.

Курс состоит из 10 уроков, предполагает 6-7 часов самостоятельной работы слушателя в неделю и в своей структуре совмещает как теоретический базис, так и практические советы профессионалов в каллиграфии. Слушатели знакомятся с используемой в данной области терминологией, включающей понятия «ключ» (部首), «графема» (偏旁) и «часть» (部分), зачастую смешиваемых и понимаемых по-разному. Например, сами китайцы считают ключом семантическую доминанту иероглифа, что и понимается под «ключом» в узком смысле. При этом термин «графема», который соотносится с китайским термином 偏旁, в русском языке обозначает все остальные части иероглифа, которые не являются ключами в узком смысле, в то время как китайцы под термином 偏旁 понимают видоизмененный вариант написания ключа 部首 в левой, правой, верхней или нижней части иероглифа. Так, «キ»-это 手旁 от 部首《手》 («рука»). Поскольку в настоящее время в связи с бумом на изучение китайского языка пользователям интернета предлагается огромное количество литературы по иероглифике, зачастую невысокого качества, слушатели имеют искаженные представления о том, что такое «ключ» и «графема». В рамках онлайн-курса по китайской иероглифике данная терминология разъясняется и приводится в систему.

Процесс изучения начинается с освоения 7 основных и более 20 комбинированных черт, слушатели учатся подсчитывать количество черт в иероглифическом знаке, определять его семантическую доминанту. Для наглядности каждый урок содержит анимированные изображения порядка черт ключа/иероглифа, а также видео, иллюстрирующее специфические особенности в написании того или иного знака, такая подача материала способствует более эффективному запоминанию знаков китайской письменности.

Шрифты и стили написания исторически были предметом особого внимания в Китае, однако в XXI в. эта проблема проявилась с новой стороны. У многих пользователей на компьютере часто предустановлены шрифты с минимальным набором символов, что приводит к невозможности отображения некоторых иероглифов. В разных шрифтах один и тот же иероглифический ключ может изображаться по-разному, например, 兑 и 兌, такие пары иероглифических знаков в уроках для слушателей выделяются особо. В рамках одного шрифта разные черты могут изображаться одинаково, например: знак $\square$ кистью пишется с ломаной вертикальной, а $\sqsubset$ - изогнутой вертикальной, но в основных шрифтах, которые используются в современных системах - SimSun ( $\sqsubset \sqsubset$ ) и KaiTi ( $\sqsubset \sqsubset$ ) , обе черты пишутся одинаково.

Во избежание этих проблем создатели курса предусмотрели возможность дублирования изображения иероглифического знака в формате JPEG или BMP. Соответственно, при разработке упражнения были исключены формы, где слушателю предлагается самостоятельно ввести иероглиф. Контрольный блок строится по тестовой системе и включает задания:

- выбрать правильное название для данного ключа;

— выбрать правильный ключ для данного названия;

- указать иероглифы с данным ключом;

- указать ключ в группе иероглифов;

- соотнести ключи и иероглифы, в которых они содержатся. 
Данный онлайн-курс является прекрасным поводом проникнуть в азы китайской иероглифики, познакомиться с многовековой традицией каллиграфии, научиться получать эстетическое удовольствие от поэтапного освоения уникального письма Поднебесной вместе с профессионалами, для изучающих же китайский язык данный курс будет прекрасным подспорьем в изучении соответствующих аспектов китайской графической системы.

Перед нами как пионерами в создании программ электронного обучения восточным языкам в России встал целый ряд проблем, часть из которых удалось в рабочем процессе успешно преодолеть, превратив их в преимущества, однако часть вызовов по-прежнему так и стоит на повестке дня.

\section{4. Основные преимущества обучения китайскому языку онлайн}

Тщательный подбор учебных материалов с учетом особенностей восточного языка, а большинство языков Востока - это экзотические системы, значительно отличающиеся от европейских языков. Онлайн-форма обучения и учет начального языкового уровня слушателя обеспечивают для всех заинтересованных достижение желаемого уровня владения им. С содержательной точки зрения, структура урока продумана и выверена за долгие годы практической педагогической деятельности создателей, все уроки организованы как увлекательные и разнообразные занятия с постоянной сменой деятельности. При условии регулярной и добросовестной работы обучающегося и, конечно же, выполнения домашних заданий по пройденному материалу, можно и даже не так сложно выучить восточный язык до среднего уровня владения (уровень А2/B1).

Обучающиеся имеют возможность задать, обсудить или найти ответ на какие-то вопросы, возникающие у них в ходе освоения материала. Для этого существует форум, где слушатели, помимо вопросов по пройденному материалу, имеют возможность поделиться своими достижениями и сомнениями с другими слушателями курса, обратиться к разработчикам по техническим вопросам или проблемам. После прохождения курса обучающийся имеет возможность получить подтверждающий факт обучения сертификат, обычно содержащий оценку успеваемости слушателя и идентификацию личности. Индивидуальный подход к каждому обучающемуся и его потребностям при сдаче контрольных заданий, позволяет достичь желаемого результата всем заинтересованным слушателям.

Для создателей курса и образовательной платформы выдача сертификатов - это один из способов покрыть свои затраты на создание курса, зачастую довольно значительные, в условиях невозможности покрытия этих расходов теми методами, которые практикуются за рубежом [3, c. 103]. Для пользователей онлайн-курсов, предоставляемых на бесплатной основе, это возможность повысить общее количество баллов в кредитно-рейтинговой системе оценки знаний студента ВУЗа, перезачесть те или иные учебные дисциплины или вписать новый навык или профессиональную компетенцию в свое резюме.

Зачастую изучение одного онлайн-курса порождает интерес и желание получить более глубокие знания и по смежным дисциплинам. В таких случаях стоит задуматься об изучении других восточных языков или о продолжении изучения выбранного языка на более продвинутом уровне. В результате слушатели имеют возможность составить для себя индивидуальную программу с уникальным наполнением и оптимальной структурой.

\section{5. Вызовы и перспективы в обучении китайскому языку онлайн}

В результате проведенных исследований было установлено, что современные технологии все еще не позволяют при изучении иностранного языка поставить произношение онлайн (это 
актуально для всех языков, не только восточных), поэтому работа над звуковой стороной во многом ложится на плечи самих слушателей. Здесь должно быть четкое понимание того, что несмотря на ИКТ, процесс обучения не носит очный характер, когда преподаватель имеет возможность исправить выявленные ошибки у учащегося, непосредственно присутствуя на аудиторных занятиях, поэтому речь идет, прежде всего, о самостоятельной работе слушателя, внимательном следовании полученным рекомендациям.

Традиция начинать курс обучения языку с освоения фонетического строя типична для любого иностранного языка, однако специфические особенности китайского, а именно слоговой и тональный характер китайского языка требуют особого внимания к звуковому строю, поэтому постановка артикуляции и отработка тонов является важнейшим аспектом изучения этого языка. Произношение для китайского языка играет ключевую роль, выполняя смыслоразличительную функцию, неверно произнесенный тон может стать причиной недопонимания между собеседниками.

Поэтому слушателям настоятельно рекомендуется заострить особое внимание на лекции по фонетике и в дальнейшем в процессе обучения периодически возвращаться к ней, чтобы закрепить и регулярно освежать в памяти комплекс артикуляторных характеристик звуков китайского языка. Работу над звуками и тонами китайского языка рекомендуется проводить без наушников, чтобы слышать самого себя. В ходе обучения со стороны преподавателя проводится регулярный мониторинг учебного процесса, однако следить за тем, как и сколько отрабатывал написание иероглифа слушатель, сколько времени он потратил на отработку тона или заучивание иероглифа и т.д., педагог не может, хотя определенные механизмы мониторинга есть и в этом.

Существует разрыв между числом регистрирующихся на онлайн-курс и успешно его завершивших. Причины недоведения начатого до победного конца, как правило, носят субъективный характер (дефицит свободного времени, знакомство с отдельными частями курса, личный интерес к изучению восточного языка без необходимости документального подтверждения факта прохождения программы и т.п.).

Поэтому методы повышения доли слушателей, прошедших обучение полностью и перешедших к следующему, более высокому уровню изучения языка, по-прежнему представляют собой некоторый вызов. Для создателей курсов, заинтересованных в массовости программ, ценными являются именно дошедшие до финишной прямой слушатели, которые путем итоговой оценки результатов обучения, монетизируют данный курс. Для слушателей успешное завершение одного курса - стимул продолжить обучение дальше [4].

Для получения сертификата о прохождении курсов слушатель должен пройти тестирование, которое стандартно проводится в режиме реального времени с помощью веб-камеры, однако полностью исключить возможность помощи со стороны или списывания в таком формате обучения крайне затруднительно.

На фоне довольно большого числа онлайн-курсов, предлагаемых преимущественно китайскими образовательными учреждениями, наблюдается отсутствие отраслевых стандартов, что лишает слушателя возможности самостоятельно определить уровень, с которого следует приступить к выбранной программе, и продолжить обучение уже на другой образовательной площадке, что, возможно, не столь актуально на начальном уровне, однако оказывается критичным при приобретении определенных профессиональных компетенций на продвинутом уровне.

Выход видится в создании системы взаимозачетов курсов, предлагаемых на разных площадках, что оказывается особенно актуально в связи с активным внедрением этого формата обучения в ведущих российских ВУЗах, статистику см. [5, с.185]. 
В целом современное образование уже очень устойчиво опирается на ИКТ, широкое распространение открытых онлайн-курсов, их активная интеграция в систему образования подтверждают востребованность подобных решений в практике преподавания практически любых дисциплин, в том числе и в ВУЗах.

Можно с уверенностью прогнозировать стремительный рост числа образовательных продуктов для нынешнего цифрового поколения обучающихся. Потенциал программ электронного обучения огромен, мы стоим на пороге возможного пересмотра системы образования в мировом масштабе. На фоне того скепсиса, который присутствует у противников массового онлайн-образования (или edutainment «образовательного развлечения», как его называют сторонники традиционных моделей обучения), чтобы адекватно оценивать перспективы и сложности процесса, недостаточно быть просто сторонними наблюдателями, мы должны быть участниками этого движения по внедрению инновационных методик и технологий, в том числе в преподавании восточных языков, чтобы остаться профессионалами до конца.

Следующим этапом развития языковых онлайн-курсов могут стать мобильные приложения для смартфона, которые позволят выполнять часть заданий по программе практически в любом месте в удобное время, что безусловно скажется на расширении целевой аудитории за счет молодежи, которая в нынешних условиях проводит большую часть времени именно в смартфоне.

Кроме того, обучение иностранному языку, тем более для осознанно стремящихся выучить экзотический восточный язык, не должно ограничиваться только лишь формированием коммуникативных навыков и подготовкой к межкультурному взаимодействию. В дальнейшей перспективе представляется важным сместить акцент на овладение узкоспециальной терминологией в рамках отдельных профессиональных направлений, развитие навыков чтения текстов по отраслевой тематике, ведение устной и письменной коммуникации по актуальным вопросам профессиональной сферы. Поэтому в будущем нас ждут и узкоспециальные онлайнкурсы «Восточный язык для специальных целей». К сожалению, пока подобные курсы отсутствуют даже в оффлайн-обучении, предоставляя лишь некоторый выбор учебных материалов в печатном виде, наиболее актуальной задачей онлайн-образования станет разработка курсов иностранных языков с более узкой специализацией «Китайский язык в сфере туризма», «Японский язык для ВЭД» и т.п.

\section{Литература}

[1]Краснова Г.А., Можаева Г.В. Электронное образование в эпоху цифровой трансформации. Томск: Издательский дом ТГУ, 2019. 200 с.

[2]Семенова Т. В., Вилкова К. А., Щеглова И. А. Рынок массовых открытых онлайн-курсов: перспективы для России // Вопросы образования. 2018. №2. С.173-197.

[3] Титова С. В. Цифровые технологии в языковом обучении: теория и практика. М.: Эдитус, 2017. $240 \mathrm{c}$.

[4]Pethuraja S. Massive Open Online Courses (MOOCs) For Everyone [Электронный ресурс] // Amazon.com: Kindle edition. 02.05.2015 URL: https:/www.amazon.com/Massive-OnlineCourses-MOOCs-Everyone-ebook/dp/B00X2NTJPY (дата обращения 15.02.2019).

[5]Рощина Я. М., Рощин С. Ю., Рудаков В. Н. Спрос на массовые открытые онлайн-курсы (MOOC) опыт российского образования // Вопросы образования. №1. С. 174-199. 


\title{
Oriental Language Training Online: Opportunities and Challenges (Based on the Implementation of E-learning Chinese Language Programs)
}

\author{
N.N. Vlasova, E.N. Kolpachkova, N.A. Somkina ${ }^{2}$ \\ Saint-Petersburg State University
}

The creation of e-learning programs for oriental languages has a number of additional problems arising from the specific features of these language systems but shifts in the traditional education model have already revealed a great demand for online courses in Chinese, Japanese and other exotic languages. Having an advantage in the form of rich practical experience in the complete absence of such projects in Russian education, the course creators follow the path of expanding, deepening and improving elearning programs in view of the global trend towards digitalization of educational services based primarily on many years of practical experience at the traditional offline university course.

Keywords: e-learning, distance learning, e-learning environment, digitalization of education, additional training, Chinese language

Reference for citation: Vlasova N.N., Kolpachkova E.N., Somkina N.A. Oriental Language Training Online: Opportunities and Challenges (Based on the Implementation of E-learning Chinese Language Programs) // Information Society: Education, Science, Culture and Technologies of the Future. Vol. 3 (Proceedings of the XXII International Joint Scientific Conference «Internet and Modern Society», IMS-2019, St. Petersburg, June 19-22, 2019). - St. Petersburg: ITMO University, 2019. P. 90 - 100. DOI: $10.17586 / 2587-8557-2019-3-90-100$.

\section{Reference}

[1] Krasnova G.A., Mozhaeva G.V. Electronic education in the era of digital transformation // Tomsk: TSU Publishing House, 2019. 200 p. (In Russian).

[2] Semenova T. V., Vilkova K. A., Shcheglova I. A. The Market of Massive Open Online Courses: Prospects for Russia // Education Issues. 2018. No.2. P.173-197.

[3] Titova S.V. Digital technologies in language learning: theory and practice. M.: Editus, 2017. 240 p.

[4] Pethuraja S. Massive Open Online Courses (MOOCs) For Everyone [Electronic resource] // Amazon.com: Kindle edition. 05/02/2015 URL: https://www.amazon.com/Massive-OnlineCourses-MOOCs-Everyone-ebook/dp/B00X2NTJPY (contact date 02/15/2019).

[5] Roshchina Ya. M., Roshchin S. Yu., Rudakov V. N. Demand for mass open online courses (MOOC) experience of Russian education // Educational Studies Moscow. No.1. P. 174-199. 